\title{
Entre Cervantes y Borges: perspectivas y desafíos
}

\author{
Sé que hay algo \\ Inmortal y esencial que he sepultado \\ En esa biblioteca del pasado \\ En que leí la historia del hidalgo. \\ (Borges: Lectores, El otro, el mismo)
}

En el año 2016 se conmemoraron 400 años de la muerte de Cervantes y 30 años de la de Borges, dos figuras centrales de la gran historia de los libros. Tomando como punto de partida este emblemático aniversario y con ocasión del 35 aniversario de los Estudios Hispánicos en la Facultad de Filosofía y Letras de la Universidad de Ljubljana, publicamos este número temático de la revista Verba Hispanica bajo el título Entre Cervantes y Borges: perspectivas $y$ desafíos. La pasión por las letras infundida a la humanidad por estos dos prestigiosos maestros con el tiempo no se ha reducido al silencio, todo lo contrario: a principios del siglo XXI, más que nunca, ante el desafío de una cultura en transformación, tenemos que preservar su presencia espiritual y artística revalorizando los múltiples mensajes de su genial capacidad de invención y proyectarlos a la vez hacia los «mundos posibles» del futuro.

Con todos los trabajos que se presentan en este número temático hemos deseado, ante todo, abrir las puertas al debate científico sobre las nuevas realidades y los retos más relevantes a los que se enfrenta el español en su vertiente lingüística, literaria y didáctica. A partir de este criterio hemos seleccionado veintiún estudios representativos organizados en las tres secciones en las que se divide el presente volúmen: a las dos secciones tradicionales -lingüística y literatura- viene a sumarse en esta edición un apartado dedicado a la didáctica.

Los estudios reunidos abarcan tanto las investigaciones que abordan directamente la obra de los dos autores, Cervantes y Borges, como los que consideran su legado innovador en el sentido más amplio de la palabra y emprenden enfoques teóricos y metodológicos del todo novedosos aplicándolos a sus 
respectivas áreas de interés. El resultado es un sugerente repertorio de las miradas más variadas.

Así, las diferentes contribuciones pertenecientes al ámbito lingúístico abarcan aspectos lingüístico-pragmáticos y léxico-semánticos, estudios contrastivos y traductológicos, incluyendo asimismo una perspectiva sociolingüística y literaria. Los estudios literarios, por su lado, siguen de cerca las infinitas posibilidades de combinación de temáticas y recursos literarios trazadas por los dos maestros-profetas que abren perspectivas cada vez más inspiradoras y singulares sobre la inmortalidad de la creación artística. Este recorrido se cierra con tres artículos orientados a la enseñanza del español que inspiran la confinaza en que toda esta riqueza fomentada por generaciones de grandes autoridades seguirá siendo transmitida a las generaciones venideras.

Expresamos nuestro agradecimiento a los autores de todos y cada uno de los artículos que respondieron a nuestra iniciativa e hicieron posible llevar a cabo este proyecto, demostrando con ello su afán por la investigación y su interés por la colaboración internacional, tan enriquecedora e indispendable en el ámbito académico. Gracias también al equipo de la revista por la dedicación invertida en las tareas de edición.

Barbara Pihler Ciglič, Maja Šabec, Marjana Šifrar Kalan 